\title{
Gentle teaching: Foundations and Strategies in Reducing Reading Disabilities
}

\author{
Mostafa Abo El-Majd Soleman, Osama Ahmed Ata and Hala Ahmed salah \\ Faculty of Education, South Valley University
}

\begin{abstract}
:
This article addressed Gentle Teaching and its foundations, strategies, supportive techniques, and strength. In addition, some Arab and foreign studies reported the effectiveness of gentle teaching. Gentle teaching has been recently introduced as a new method to treat problems as an alternative method of classical control directive in treatment. It aims to teach how to correlate, reliance on others in a manner characterized by courtesy, observe, respect and cooperate, with focusing on the importance of unconditional assessment in education. The foundations of this method were democratic versus authoritarian values, posture as center of the teaching- learning process, avoiding punishment, the interactional view of behavior, technology as a method, human reward, interactional equality and moving toward equitable interactions. While reward, ignoring, redirection, and interruption were presented as the strategies of gentle teaching. The supportive techniques which were errorless teaching, task analysis, environmental variables, coparticipation, dialogue of unconditional valuing, shaping, reinforcement, giving choices and reward envelopes. Also, some foreign studies reported the effectiveness of this method in reducing learning disabilities and reading difficulties..
\end{abstract}

Keywords: Gentle Teaching; Reading Disabilities

Citation Soleman et al.,Requirements of Electronic Management in the Management of

Kindergarten Institutions. SVU-Journal of abstract 2019, Vol.1: pp22 (retrieved from the Journal of Educational Sciences; 2018, No.35; pp 431) .

Copyright: Publisher South Valley University. This is an open-access article distributed under the terms of the creative commons attribution license, which permits unrestricted use, distribution and reproduction in any medium provided the original author and source are created. 